\title{
Reinforcement parameters and schedule interaction: Performance maintained by multiple schedules
}

\author{
JOĀO CLAUDIO TODOROV and JÚLIO ROMERO FERREIRA \\ Universidade de Brasilia, 70000 Brasilia, DF, Brazil
}

\begin{abstract}
Pigeon's keypecks were maintained under a multiple variable-interval, variable-interval schedule of reinforcement. Changes in response rates in both schedule components were observed for conditions where reinforcement frequency and magnitude (duration of access to food) differed between components. Reinforcement frequency was more potent than reinforcement magnitude in determining response rate, but the effects of both variables depended also on component duration and on presence or absence of time-outs separating components.
\end{abstract}

In a multiple schedule, reinforcement is arranged by two or more alternating schedules, each schedule being accompanied by an appropriate stimulus. When one schedule is in effect, the other is not. Changes in schedules are determined by the experimenter, so the subject has no control over which schedule will be in force at a given time. In concurrent schedules, two or more independent schedules are arranged simultaneously, each associated with a different operant. At any time, the subject may respond in the presence of a stimulus associated with one or another schedule. In spite of these differences in contingencies, data from studies of responding in both situations may be described by similar equations (Baum, 1974; Herrnstein, 1970). Critical factors in the comparison of behavior maintained by multiple and by concurrent schedules are component duration and changeover rate (in multiple and concurrent schedules, respectively).

With short component durations, behavior under multiple schedules is similar to that maintained by concurrent schedules (Killeen, 1972; Shimp \& Wheatley, 1971; Todorov, 1972). When changeovers in concurrent schedules are penalized, interchangeover times are longer and responding is similar to that maintained by multiple schedules of long component duration (Todorov, 1971).

The main focus of the present investigation is the effect of timeouts separating components in multiple schedules. In previous investigations of the effect of component durations on responding, components alternated singly (Killeen, 1972; Shimp \& Wheatley, 1971; Todorov, 1972). In this experiment, the effect of a timeout separating components was observed for: (1) short and long component durations and (b) equal and

The authors are indebted to Manoel Carneiro Aguiar for help in different phases of this work. Reprints may be obtained from either author, Departmento de Psicologia, Universidade de Brasilia, 70000, Brasilia, DF, Brazil. This paper is sponsored by Richard L. Shull who takes full responsibility for its content. unequal reinforcement magnitude (duration of access to food).

\section{METHOD}

\section{Subjects}

Four male experimentally naive adult pigeons from uncontrolled derivations of the species Columba livia, caught wild, were maintained at $80 \%$ of free-feeding weight.

\section{Apparatus}

A Grason-Stadler pigeon chamber with two response keys (Model 1121) was used. The right response key was inoperative throughout the experiment. The left key could be transilluminated by a red or green light. A minimum force of $11 \mathrm{~N}$ was required to operate the response key. White noise from a speaker inside the chamber masked operation of relays. Electromechanical equipment controlled programming and recording of events. The reinforcer was a period of access to food (a balanced mixture of powdered cereals).

\section{Procedure}

Schedules. A mult VI $1 \mathrm{~min}$, VI $3 \mathrm{~min}$ was in effect throughout the experiment. Reinforcement frequency was scheduled through tapes with arithmetic distribution of interreinforcement periods. Tape programmers ran successively; when one programmer was operated, the other was not. During reinforcement and time-out, both programmers stopped.

Stimuli. The response key was transilluminated by a green light during VI $1 \mathrm{~min}$ and by a red light during VI $3 \mathrm{~min}$. A houselight was located to the left of the panel. Key- and houselights were off during reinforcements and time-out periods.

Component alternation. Components alternated singly and had equal durations in each experimental condition (10 or $180 \mathrm{sec}$ ). In half of the conditions, a time-out of $5 \mathrm{sec}$ separated components. The initial component of all daily sessions was VI $1 \mathrm{~min}$ in half of the sessions and VI $3 \mathrm{~min}$ in the other half, alternating each day.

Experimental conditions. Table 1 shows all experimental conditions. Three independent variables were manipulated: reinforcement duration (15 sec of access to food associated with each VI schedule, or $10 \mathrm{sec}$ to one and $30 \mathrm{sec}$ to the other one); component duration (10 or $180 \mathrm{sec})$; and component separation (with or without a 5 -sec time-out). Since VI tape programmers stopped during reinforcement, reinforcement duration was not included in component duration.

A session ended after a fixed number of components: 20 
Table 1

Experimental Conditions, Sequence Used for Each Subject, and Total Responses Per Hour from the Last Five Sessions in Each Condition

\begin{tabular}{|c|c|c|c|c|c|c|c|}
\hline \multirow{2}{*}{$\begin{array}{l}\text { Compo- } \\
\text { nent } \\
\text { Dura- } \\
\text { tion } \\
\text { (Sec) }\end{array}$} & \multicolumn{2}{|c|}{$\begin{array}{c}\text { Reinforce- } \\
\text { ment } \\
\text { Duration } \\
\text { (Sec) }\end{array}$} & \multirow{2}{*}{$\begin{array}{l}\text { Compo- } \\
\text { nent } \\
\text { Separa- } \\
\text { tion }\end{array}$} & \multirow{2}{*}{$\begin{array}{l}\text { Cond. } \\
\text { Order }\end{array}$} & \multicolumn{2}{|c|}{ Resp/Hour } & \multirow[b]{2}{*}{ essions } \\
\hline & VI 1 & VI 3 & & & VI 1 & VI $3 s$ & \\
\hline & & & Bird 180 & & & & \\
\hline 180 & 15 & 15 & Time-Out & 1 & 5428 & 3272 & 19 \\
\hline 180 & 10 & 30 & Time-Out & 2 & 4510 & 3297 & 24 \\
\hline 180 & 15 & 15 & & 7 & 4508 & 3526 & 8 \\
\hline 180 & 10 & 30 & & 8 & 3330 & 2426 & 15 \\
\hline 10 & 15 & 15 & Time-Out & 5 & 7205 & 5679 & 9 \\
\hline 10 & 10 & 30 & Time-Out & 6 & 6858 & 6400 & 18 \\
\hline 10 & 15 & 15 & & 4 & 6472 & 2066 & 13 \\
\hline \multirow[t]{2}{*}{10} & 10 & 30 & & 3 & 7631 & 4082 & 17 \\
\hline & & & Bird 181 & & & & \\
\hline 180 & 15 & 15 & Time-Out & 1 & 5206 & 3093 & 9 \\
\hline 180 & 10 & 30 & Time-Out & 2 & 3703 & 3111 & 43 \\
\hline 180 & 15 & 15 & & 8 & 3990 & 3230 & 9 \\
\hline 180 & 10 & 30 & & 3 & 3508 & 3742 & 10 \\
\hline 10 & 15 & 15 & Time-Out & 6 & 3127 & 2887 & 9 \\
\hline 10 & 10 & 30 & Time-Out & 7 & 3519 & 4221 & 12 \\
\hline 10 & 15 & 15 & & 4 & 3504 & 1901 & 26 \\
\hline \multirow[t]{2}{*}{10} & 10 & 30 & & 5 & 3949 & 2582 & 11 \\
\hline & & & Bird 182 & & & & \\
\hline 180 & 15 & 15 & Time-Out & 1 & 4332 & 3000 & 19 \\
\hline 180 & 10 & 30 & Time-Out & 2 & 5929 & 5061 & 8 \\
\hline 180 & 15 & 15 & & 7 & 5964 & 4547 & 9 \\
\hline 180 & 10 & 30 & & 8 & 5358 & 4673 & 8 \\
\hline 10 & 15 & 15 & Time-Out & 3 & 7629 & 7910 & 14 \\
\hline 10 & 10 & 30 & Time-Out & 6 & 5902 & 6138 & 12 \\
\hline 10 & 15 & 15 & & 4 & 6506 & 3890 & 14 \\
\hline \multirow[t]{2}{*}{10} & 10 & 30 & & 5 & 6074 & 4758 & 25 \\
\hline & & & Bird 183 & & & & \\
\hline 180 & 15 & 15 & Time-Out & 1 & 5264 & 3820 & 9 \\
\hline 180 & 10 & 30 & Time-Out & 2 & 4899 & 4311 & 24 \\
\hline 180 & 15 & 15 & & 7 & 5859 & 4490 & 9 \\
\hline 180 & 10 & 30 & & 8 & 4331 & 4039 & 11 \\
\hline 10 & 15 & 15 & Time-Out & 3 & 7307 & 6184 & 21 \\
\hline 10 & 10 & 30 & Time-Out & 6 & 7248 & 6566 & 15 \\
\hline 10 & 15 & 15 & & 4 & 7310 & 2563 & 12 \\
\hline 10 & 10 & 30 & & 5 & 6841 & 2983 & 14 \\
\hline
\end{tabular}

when component duration was $180 \mathrm{sec}$ and 360 when component duration was $10 \mathrm{sec}$.

Any condition was in effect for a minimum of eight daily sessions and until relative response rates in one of the components (response rate in one component divided by the sum of response rates in both components) did not vary in excess of .05 between any two of five consecutive sessions.

\section{RESULTS}

Table 1 summarizes total responses per component from the last five sessions in each condition. Figure 1 shows the effects of time-out separating components on rate of responses in VI $1 \mathrm{~min}$ and in VI $3 \mathrm{~min}$, for each subject. Data represent means of total number of responses across four subjects in all experimental conditions (individual data are presented in Table 1). Filled bars indicate response rates in conditions where a time-out was used to separate components; unfilled bars show rates when components alternated directly. A comparison of the upper graphs (180-sec component duration) with the lower ones (10-sec component duration) shows that the 5-sec time-out had a considerable effect only when the short component duration was used. This effect was clearly on responding controlled by the VI 3-min schedule ( 20 reinforcements per hour); response rates were considerably higher when a time-out separated components. When reinforcement magnitude was equal for both schedules, total number of responses in VI 3 min was 2,600 when components alternated directly and 5,600 when there was a timeout between components (lower left graph). For unequal reinforcement magnitudes, there were 3,600 responses in

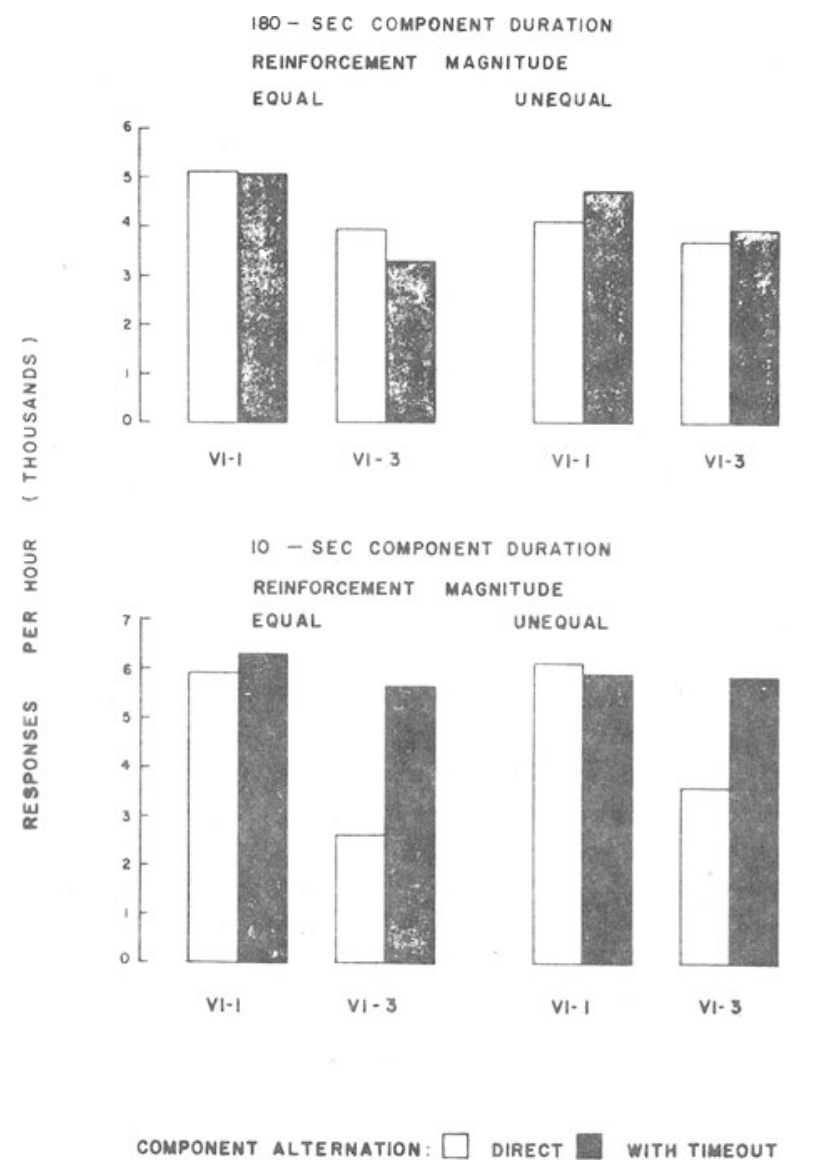

Figure 1. Effects of time-out separating components on absolute rates of responding in VI $1 \mathrm{~min}$ and VI $3 \mathrm{~min}$ averaged across subjects. Conditions where reinforcement magnitude was equal on both schedules are shown on graphs on the left side. Conditions where reinforcement magnitude in VI 3 min was three times the reinforcement magnitude in VI $1 \mathrm{~min}$ are shown on graphs on the right side. Upper graphs show data from conditions where component duration was $180 \mathrm{sec}$, and lower graphs show data from conditions where component duration was $10 \mathrm{sec}$. Empty columns indicate conditions where components alternated directly, and filled columns where a timeout separated components. 
the condition without a time-out and 5,800 responses in the condition with. No systematic effect of the time-out period on responding was observed in the other experimental conditions.

The effect of unequal reinforcement magnitude associated with components schedules is more evident for the short component duration, with no time-out between components. If total access to food per schedule component (frequency of reinforcements times duration of access to food per reinforcement) were used as the independent variable, conditions would be the same for both component schedules, since both 20 reinforcements per hour associated with reinforcement duration of $30 \mathrm{sec}$ and 60 reinforcements per hour associated with reinforcement duration of $10 \mathrm{sec}$ provide $600 \mathrm{sec}$ of access to food per hour. However, with component duration of $10 \mathrm{sec}$ and no time-out between components (lower graph in Figure 1, unfilled bars), response rate in VI $1 \mathrm{~min}$ was about the same for the "equal" and "unequal" conditions of reinforcement magnitude. Response rate in VI $3 \mathrm{~min}$ was higher when reinforcement magnitude was $30 \mathrm{sec}$ than when it was $15 \mathrm{sec}$, but it was about half of the rate in VI $1 \mathrm{~min}$ with 10-sec reinforcement magnitude.

In the conditions where component duration was $10 \mathrm{sec}$ and a time-out separated components (lower graphs, filled bars), response rate was equally insensitive to differences in frequency or magnitude of reinforcement.

\section{DISCUSSION}

The data from this experiment: (a) confirm the findings of Shimp and Wheatley (1971) and Todorov (1972) that response distribution in mult VI VI is a function of component duration but indicate that this relation may be modified by the conditions prevailing at the transition from one schedule to another; (b) extend to mult VI VI the findings of Todorov (1973) and Schneider (1973) that reinforcement frequency has a more potent effect on response distribution than reinforcement magnitude, but indicate that in multiple schedules the effects of reinforcement frequency and magnitude may be modified by changes in component duration and in the conditions prevailing at the moment where components alternate.
The use of a 5-sec time-out period separating components had a drastic effect on responding when component duration was 10 sec: subjects tended to respond at the same rate in both components. While responding during the VI 1-min component was not systematically affected by the time-out period, responding during VI 3 min was higher when a time-out period was used. The data indicate that in these conditions (short component duration and time-out between components), changes in both reinforcement frequency and magnitude had little or no effect on rate of responding.

The analysis of effects of reinforcement frequency and magnitude in mult VI VI reveals that, as in conc VI VI (Schneider, 1973; Todorov, 1973), reinforcement frequency may be more potent than reinforcement magnitude in determining response rate. The greater power of reinforcement frequency was more evident with components of short duration alternating singly, a condition closer to that observed in concurrent schedules.

\section{REFERENCES}

BAum, W. M. On two types of deviation from the matching law: Bias and undermatching. Journal of the Experimental Analysis of Behavior, 1974, 22, 231-242.

HerRnstein, R. J. On the law of effect. Journal of the Experimental Analysis of Behavior, 1970, 13, 243-266.

KILleEN, P. A yoked-chamber comparison of concurrent and multiple schedules. Journal of the Experimental Analysis of Behavior, 1972, 18, 13-22.

SChNeIDER, J. W. Reinforcer effectiveness as a function of reinforcer rate and magnitude: A comparison of concurrent performances. Journal of the Experimental Analysis of Behavior, 1973, 20, 461-471.

Shimp, C. P., \& Wheatley, K. L. Matching to relative reinforcement frequency in multiple schedules with a short component duration. Journal of the Experimental Analysis of Behavior, 1971, 15, 205-210.

Todorov, J. C. Concurrent performances: Effect of punishment contingent on the switching response. Journal of the Experimental Analysis of Behavior, 1971, 16, 51-62.

Todorov, J. C. Component duration and relative response rates in multiple schedules. Journal of the Experimental A nalysis of Behavior, 1972, 17, 45-49.

ToDorov, J. C. Interaction of frequency and magnitude of reinforcement on concurrent performances. Journal of the Experimental Analysis of Behavior, 1973, 19, 451-458.

(Received for publication August 20, 1975. 